the results of technical progress and to apply scientific knowledge in fire-fighting and prevention. Since 1930, the International Association of Fire Chiefs has been responsible for a programme of training and development, and in 1937 fireman training schools wero organized in connexion with State programmes of rocational education in twenty-two States, in which 5,441 firemen were enrolled. The training programmes include a system of zone or regional schools for training within a wide area; extension classes, chiefly in connexion with a State college or university; short courses or institutes providing three to five days of instruction annually; and local training programmes in the larger cities. Vocational training agencies appear to be of assistance chiefly in the training of instructors or conference leaders ; the organization of instructors' conferences ; the supervision of training programmes, particularly in the zone schools; the provision of instruction in practical and technical subjects through extension classes or short courses and the supply of literature for instruction and teaching. The bulletin also discusses the methods of assisting a local fire department in organizing a training programmo and the possibilities of co-operation with other agencies. Details of the organization and administration of the Massachusetts zono schools aro appended and also of the California programme.

\section{Hygiene and Public Health in India}

THe annual report of the All-India Institute of Hygiene and Public Health, Calcutta, recently issued, summarizes the teaching and research work for the year 1937. Statistical investigations on cholera havo been pursued ; for example, foreeasts of epidemics, and research on variations in tho chemical structure and antigenic properties of the cholera vibrio. An inquiry into the nature of an obscure disease, epidemic dropsy, has incriminated mustard oil (much used in cooking) as the causative agent, though what constituent of it is responsible still remains to be discovered. An account of the work of the Maternity and Child Welfare Centre is included.

\section{Tuberculosis in Cyprus}

The National Association for the Prevention of Tuberculosis has published an interim report on the incidence and means of control of tuberculosis in Cyprus ("Tuberculosis in Cyprus", by N. D. Bardswell. II. D. Adlard and Son, Ltd., 21 Hart Street, IV.C.I. 2s. 6d.). Tuberculosis was said to be rife in the island and to be increasing rapidly; the assistance of the National Association was requested, and Dr. Bardswell was appointed to conduct an inquiry in the island. A total of 250-300 notifications of pulmonary tuberculosis a year is recorded in a population of some 360,000 . If a correct record, this would give a notification rate for pulmonary tuberculosis of less than $1 \cdot 0$ per 1,000 living - -not a high rate, for the present rate (1935) for England and Wales is 0.97 , and for London $\mathbf{1 \cdot 2} \mathbf{T}$, per 1,000 living. There is reason to think, however, that the notification returns are inaccurate, and do not represent more than onequarter to one-half of the now cases occurring annually, owing to failures to notify all cases and to inaccuracies in diagnosis. Dr. Bardswell has surveyed the whole island, and the results of tuberculin testing in some districts are given. The report contains a mass of details, and is well illustrated with maps, plans, charts and photographs. It is difficult, however, to gather the actual facts and conclusions from this report of 228 pages, for it contains no table of contents, no index, and no general summary; theso omissions should be made good in any further report.

\section{Scientific Uses of Cinematography}

ThF British Film Institute, 4 Great Russell Street, London, W.C.1, one of the objects of which is to collect and disseminate information concerning the use of films for educational purposes, is engaged in compiling a bibliography on the scientific uses of cinematography. Very few books have been written on the subject and the list will consist almost entirely of references to reports of scientific associations and to articles which have appeared in scientific and film journals. The Institute would be glad to receive any information bearing on the undertaking.

\section{Water Speed Record}

Sir Malcoly Campbell set up a now record for speed on water on August 19 with his motor-boat Bluebird II on Coniston Water. Tho speeds reached over a statute mile in opposite directions were 142.85 and 140.62 miles an hour respectively, the average being returned as 141.74 miles an hour. Sir Malcolm's boat, in the design of which some novel features were embodied, was driven by a twelve-year-old engine intended for practice runs.

\section{Recent Sunspot Activity}

THE appearance this week of a large group of sunspots serves as a reminder that the sun is still very active though past the peak of the present 11-year sunspot cycle. This sunspot group, in latitude $13^{\circ} \mathrm{N}$., crossed the central meridian on August $21 \cdot 9$ and will pass off the western edge of the disk on August 28. The aggregate area of the component spots on August 18 was 1,300 millionths of the sun's visible hemisphere. Since the last note on sunspots (NATURE, July 15, p. 109) a number of fair-sized spots have appeared of area greater than 500 millionths but less than 1,000 millionths. The respective times of central meridian passage (communicated by Greenwich) are as follows: July $17 \cdot 1^{\mathrm{d}}, 17 \cdot 7^{\mathrm{d}}, 20 \cdot 1^{\mathrm{d}}, 23 \cdot 4^{\mathrm{d}}$, August $4 \cdot \delta^{\mathrm{d}}, 7 \cdot \hat{\delta}^{\mathrm{d}}$ and $11 \cdot 1^{\mathrm{d}}$ U.T.

\section{The Night Sky in September}

TuE autumnal equinox on September 23 brings equality of day and night the world over; thereafter (until December 22) the nights increase their duration in the northern hemisphere. The moon is new on September 13 and full (the Harvest Moon) on September 28. Jupiter is in conjunction with the moon on September 1 and 28 : Saturn on September 3 and

(Continued on p. 375) 
30: Mars on September 23. Mars, Jupiter and Saturn are the triad of evening stars. Mars, post. opposition, decreases from mag. -1.8 to mag. $-1 \cdot 1$. Jupiter is in opposition on September 27 and reaches its greatest brightness (mag. - 2.5). Close groupings of Jupiter's four inner satellites aro seen at $0 \mathrm{~h} .15 \mathrm{~m}$. on September 5 (satellite II in eclipse), 6, 13, 23, and 30 . The ring system of Saturn has now reached its most open phase for this year. The variable star, Algol, is well placed for observation all night. The Pleiades riso in the late evenings "like a swarm of fireflies tangled in a silver braid". The chief interest, however, on clear moonless nights in autumn is the region of the Milky Way. Apart from its remarkable structurestar clouds, dark rifts and "coal sacks", and gaseous nebulæ, the galactic plane is also the preferential region for classes of stars of peculiar interest, nove Cepheid variables and 0 -type stars. In the direction of the rich fields of Sagittarius lies the centre of our stellar system more than 30,000 light years away and obscured from sight by absorbing tracts of cosmic dust and of gas. Tracing a path slightly inclined to the Milky Way is a belt of bright stars that includes the brightest stars in Orion, Taurus, Cassiopeia, Cygnus and Lyra. These stars and others of the brighter $B$-type and $A$-type are representatives of a relatively small local cluster that is some 2,000 light years in diameter and contains the solar system. The average star density of the Milly. Way fields is about 40,000 stars per square degree; towards the poles of the galaxy the density falls to about 1,200 stars. The 100-inch telescope at the Mount Wilson Observatory has recorded with exposures of 200 minutes on fields at the north galactic pole as many recognizable nebula per unit area of the sky as stars! These remote stellar systems are exemplified by the great Andromeda Nebula visible to the unaided eyo as a hazy patch near the star $v$ Andromedx.

\section{Announcements}

Ar the first meeting of the Council of the newly formed Gas Research Board of the gas industry, it was announced that the first president of the Board would be Sir David Milne-Watson. The appointment of the secretary of the Institution of Gas Engineers as the first secretary of the Board was confirmed.

Tre Medical Research Council has appointed Dr. Donald Hunter, physician to the London Hospital, and Mr. Harold E. Clay, national secretary of the Passenger Services Group, Transport and General Workers' Union, to be members of the Industrial Health Research Board, in succession to Prof. J. A. Nixon and Mr. R. Coppock.

Tre College of Physicians of Philadelphia has awarded tho Alvarenga Prize to Dr. Harry Goldblatt, professor of experimental pathology and associate director of the Institute of Pathology, Western Reserve University, Cleveland, Ohio, for his out. standing contributions to the pathogenesis of hypertension.
A representative body of members of the Institu. tion of Civil Engineers is sailing from Liverpool on August 26 to participate, at the invitation of the American Society of Civil Engineers, in a BritishAmerican Engineering Congress opening in New York on September 4, and to visit the World's Fair and various places of engineering interest. The party numbers about a hundred, coming not only from Great Britain but also from India, Australia, South Africa, Nigeria, Iran and Palestine, under the leadership of Mr. W. J. E. Binnie, president of the Institution. It is thirty-five years ago since an official visit to America was made by members of the Institution.

THe fifty-second annul conference of the Sanitary Inspectors' Association will be held at Bournemouth on September 4-9 under the presidency of Mr. J. C. Dawes. Further information can be obtained from tho secretary, 18 Grosvenor Place, London, S.WT.1.

THe American Association of Biophysics and Cosmobiology is organizing an international congress of biophysics, biocosmics and biocracy to be held in New York on September 11-17 with Prof. D. Arsonval, Branly, Langevin and Tchijeskvy as honorary presidents. Further information can be obtained from the general secretary, 39 rue Scheffer, Paris $16^{\mathrm{e}}$.

Tre seventh Congress of the French Society of Phoniatrics will be held on October 17 at the Paris Faculty of Medicine when Dr. Pichon and MIme. Borel-Maisonny will read a paper on aphasia and psychogenic disorders of speech. Further information can be obtained from the general secretary, Dr. Tarneaud, 27 avenue de la Grande-armée, Paris $16^{\mathrm{e}}$.

A European Conference on Rural Life will be held under the auspices of the League of Nations in Geneva during October 16-31. The Conference will bo devoted to the well-being and solidarity of European rural life. Preliminary information, national monographs and technical documentation are being published in this connexion by Messrs. Allen and Unwin, 40 Museum Street, London, WV.C.1. Further information can be obtained from the Secretary, League of Nations, 16 Northumberland Avenue, London, W'.C.2.

A QUarterly review of philosophical books and periodicals in the form of brief excerpts and synopses will make its appearance in the early part of October of this year under the titlo Philosophic Abstracts. The intention is not only to present English-speaking philosophy departments with a bibliography of essential philosophical literature, but also to give them an opportunity of keeping abreast with the principal philosophical theories as presented by their respective authors. The editorial offices are at 884 Riverside Drive, New York, N.Y.

Dr. Hernert H. Brown, one of the signatories of the letter entitled "Sponge Mortality in the Bahamas" which appeared in NATure of May 13, p. 807 , has written pointing out that his name is incorrectly printed as "Hubert H. Brown" at the end of the letter. 